\title{
Effects of Different Doses of Fentanyl on the Sedation of Infants Under Mechanical Ventilation; A Randomized Clinical Trial
}

\author{
Bita Najafian', Hamed Eyvazloo², Mohammad Hossein Khosravi ${ }^{3,4 *}$ \\ ${ }^{1}$ Department of Pediatrics, Faculty of Medicine, Baqiyatallah University of Medical Sciences, Tehran, Iran \\ ${ }^{2}$ Department of Clinical Pharmacy, Faculty of Pharmacy, Pharmaceutical Sciences Branch, Islamic Azad University \\ (IAUPS), Tehran, Iran \\ ${ }^{3}$ Student Research Committee (SRC), Baqiyatallah University of Medical Sciences, Tehran, Iran \\ ${ }^{4}$ International Otorhinolaryngology Research Association (IORA), Universal Scientific Education and Research \\ Network (USERN), Tehran, Iran
}

*Corresponding Author: Mohammad Hossein Khosravi, M.D., Student Research Committee (SRC), Baqiyatallah University of Medical Sciences, Mollasadra St., Vanaq Sq., Tehran, Iran. Tel: +98-21-81263617,

Email: dr.mhkhosravi@gmail.com

Received August 1, 2017; Accepted August 27, 2017; Online Published November 13, 2017

\begin{abstract}
Background: Respiratory distress syndrome (RDS) is a medical emergency in infants resulting from a lack of or deficiency in surfactant, and leads to pulmonary failure. Surfactant and mechanical ventilation are among the primary treatments for helping infants with respiration. Some sedative drugs, such as benzodiazepines and opioids, are used to reduce stress and restlessness in infants under mechanical ventilation.

Objective: This study aimed to evaluate the effect of 2 different dosages of Fentanyl on sedation of infants under mechanical ventilation.

Methods: In this randomized clinical trial, infants with RDS were assessed, and restless infants under mechanical ventilation were included in the trial. Infants were randomly allocated into 2 groups. Infants in group A underwent treatment with 0.5 $\mu \mathrm{g} / \mathrm{kg}$ fentanyl, and those in group B received $1 \mu \mathrm{g} / \mathrm{kg}$ of fentanyl. Demographic information as well as data on the duration of mechanical ventilation, length of hospital stay, and need for re-intubation were recorded on a pre-designed checklist. Results: Ultimately, 60 infants (46 male and 14 female) with a mean gestational age of $36.7 \pm 1.48$ weeks in group A and $36.2 \pm 1.42$ weeks in group B underwent analysis $(P=0.087)$. Patients in group A were hospitalized for $10.36 \pm 3.59$ days, and those in group $B$ were hospitalized for $10 \pm 3.95$ days $(P=0.642)$. Mean duration of mechanical ventilation was $3.96 \pm 2.02$ days in group $A$ and $3.51 \pm 1.5$ days in group $B$ infants $(P=0.459)$.

Conclusion: The findings of the present study suggest that both doses of fentanyl $(0.5 \mu \mathrm{g} / \mathrm{kg}$ and $1 \mu \mathrm{g} / \mathrm{kg})$ reduced all parameters of respiratory distress, such as heart rate and respiratory rate, with no significant difference between the 2 doses. Keywords: Fentanyl, Infantile Respiratory Distress Syndrome, Mechanical Ventilation
\end{abstract}

\section{Background}

Affecting nearly $1 \%$ of all deliveries worldwide, respiratory distress syndrome (RDS) is a medical emergency in infants which results from the lack of or deficiency in surfactant and leads to pulmonary failure. ${ }^{1,2}$ In fact, infants are at a higher risk for RDS because of their anatomical differences with adults. RDS is usually presented with grunting, nasal flaring, and intercostal retractions. ${ }^{3}$

Surfactant and mechanical ventilation are among the primary treatments to help infants with respiration. ${ }^{4,5}$ Even after mechanical ventilation, infants show restlessness and stress because of abnormal and incomplete breathing, and this stress effectively results in altered lung function. ${ }^{6}$
Some sedative drugs, such as benzodiazepines and opioids, are used to reduce infants' stress and restlessness under mechanical ventilation. ${ }^{7-10}$

Morphine and fentanyl are 2 opioid drugs that are used for this purpose. ${ }^{11,12}$ Fentanyl is used in dosages ranging from $0.5 \mu \mathrm{g} / \mathrm{kg}$ to $4 \mu \mathrm{g} / \mathrm{kg}$ to sedate infants. According to previous studies, fentanyl has been used to reduce pain, stress, and respiratory rate in infants under mechanical ventilation; acceptable results were achieved in both intervention and placebo groups. ${ }^{13}$

\section{Objective}

According to abovementioned controversies the present

Copyright $\odot 2017$ The Author(s). This is an open-access article distributed under the terms of the Creative Commons Attribution License (http:// creativecommons.org/licenses/by/4.0), which permits unrestricted use, distribution, and reproduction in any medium, provided the original work is properly cited. 
study evaluated the effects of 2 different dosages of fentanyl on the sedation of infants under mechanical ventilation.

\section{Methods}

This randomized clinical trial was conducted between July 2016 and March 2017 at Najmiyeh University Hospital, Tehran, Iran. Figure 1 shows a flowchart of the trial. Infants with a confirmed diagnosis of RDS based on chest radiography and physical examination by a single neonatologist were assessed for eligibility using simple random sampling method. Restless infants who were under mechanical ventilation were included in the trial. Infants with weights less than $2.5 \mathrm{~kg}$ or more than $4 \mathrm{~kg}$ as well as those with congenital heart disease, brain anomalies, or metabolic or chromosomal syndromes were excluded from the study.

After explaining the study process to parents and obtaining informed consent for participation, the infants were randomly allocated to 2 groups using the random number table. The first group (A) underwent treatment with fentanyl $0.5 \mu \mathrm{g} / \mathrm{kg}$, and the second group (B) received $1 \mu \mathrm{g} / \mathrm{kg}$ of fentanyl. Demographic information and data on gestational age, birth weight, and method of delivery were recorded. Duration of mechanical ventilation, length of hospital stay, need for re-intubation, arterial oxygen pressure, and complications such as pneumothorax and hyporeflexia were recorded on a pre-designed checklist.

Data was analyzed using the Statistical Package for Social Sciences (SPSS) for Windows (version 21, IBM Corp., Armonk, NY). Sample size was calculated using "N= 2(Z 1- $\alpha+Z$ 1- $\beta) 2$ * $\mathrm{P}(1-\mathrm{P}) /(\mathrm{P} 0-\mathrm{P} 1) 2$ " formula.
Normally distributed variables (approved by the 1-sample Kolmogorov-Smirnov test) were compared between groups using the independent sample $t$ test. The chi-square test was used to compare categorical variables in the 2 groups. Mean and standard deviation (SD) were used to describe categorical variables.

\section{Results}

Ultimately, 60 infants (46 male and 14 female) with a mean gestational age of $36.7 \pm 1.48$ weeks in group A $(0.5 \mu \mathrm{g} / \mathrm{kg}$ fentanyl $)$ and $36.2 \pm 1.42$ weeks in group B $(1 \mu \mathrm{g} / \mathrm{kg}$ fentanyl $)$ were analyzed $(P=0.087)$. Of all study infants, $8(13.3 \%)$ were natural vaginal deliveries, and $52(86.7 \%)$ infants were delivered by cesarean section. Table 1 shows the pregnancyrelated complications observed in the study individuals. There were no cases of addiction, chorioamnionitis, or decollement. RDS was the most prevalent $(83.3 \%)$ cause of hospitalization followed by pneumonia (5\%), meconium aspiration (3.3\%), and asphyxia (1.7\%). Mean birth weight was $2.85 \pm 0.5 \mathrm{~kg}$ in group A and $2.84 \pm 0.61$ in group B infants $(P=0.940)$. During the study, $57(95 \%)$ infants needed surfactant, $6(10 \%)$ received phenobarbital, and 2 (3.3\%) received phenobarbital. $\mathrm{N}$-acetyl cysteine was not prescribed for any of the infants.

For all study individuals, mean duration of hospitalization was 10.18 \pm 3.74 days. Patients in group A and B were hospitalized for $10.36 \pm 3.59$ days and $10 \pm 3.95$ days, respectively $(P=0.642)$. Infants underwent mechanical ventilation for an average of $3.74 \pm 1.78$ days. Mean duration of mechanical ventilation was $3.96 \pm 2.02$ days

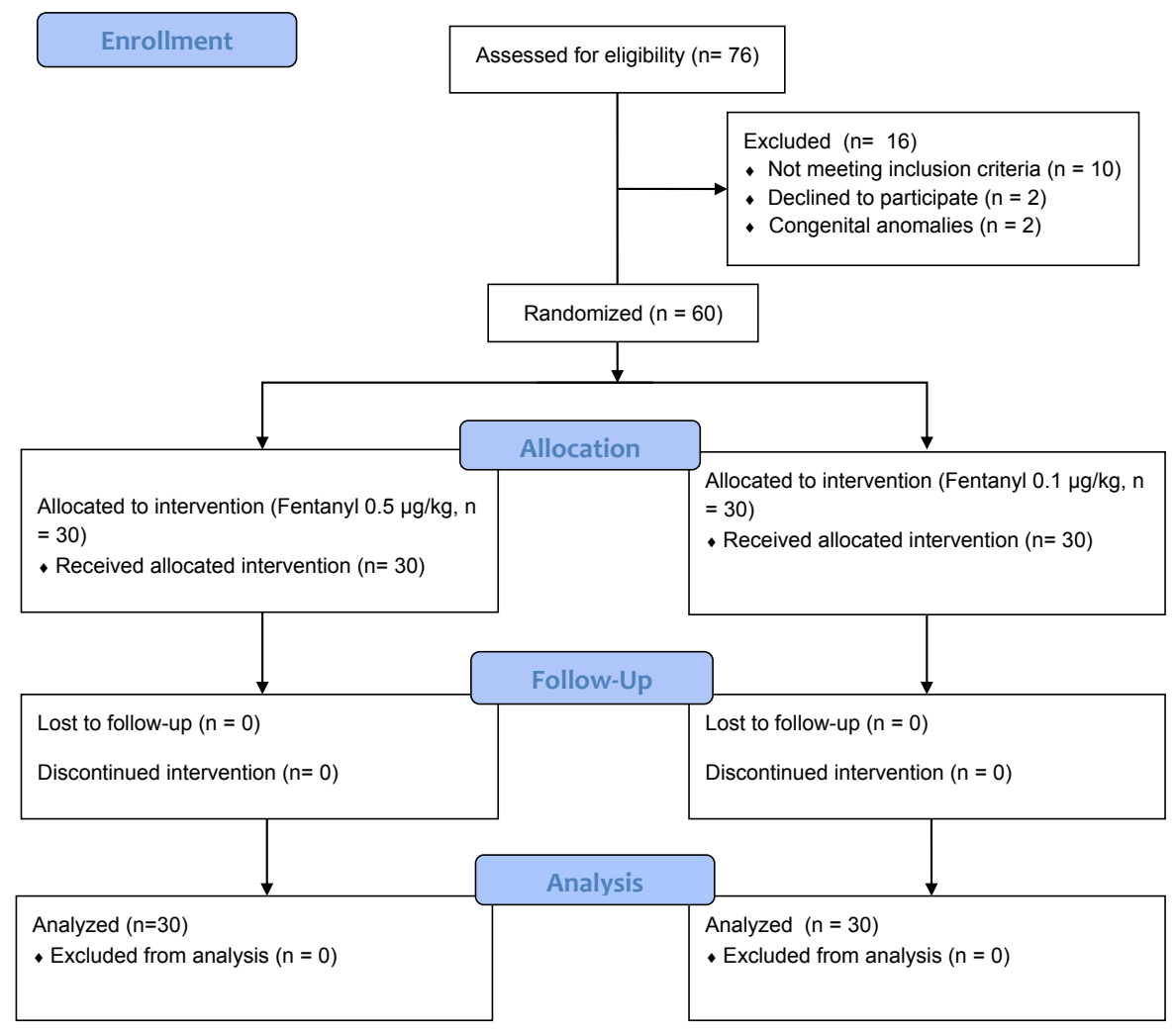

Figure 1. Study Flowchart. 
Table 1. Pregnancy-Related Complications in Study Individuals

\begin{tabular}{lccc}
\hline Complication & $\begin{array}{c}\text { Group A } \\
(\mathbf{n}=\mathbf{3 0})\end{array}$ & $\begin{array}{c}\text { Group B } \\
(\mathbf{n}=\mathbf{3 0})\end{array}$ & $\boldsymbol{P}$ Value \\
\hline Gestational diabetes & 2 & 7 & 0.071 \\
Hypertension & 2 & 1 & 0.554 \\
PROM & 0 & 1 & 0.313 \\
Thick meconium & 2 & 2 & 0.998 \\
\hline
\end{tabular}

Table 2. Need for Additional Dose During Trial in Detail

\begin{tabular}{lccc}
\hline Complication & $\begin{array}{c}\text { Group A } \\
(\mathbf{n}=\mathbf{3 0})\end{array}$ & $\begin{array}{c}\text { Group B } \\
(\mathbf{n}=\mathbf{3 0})\end{array}$ & $\boldsymbol{P}$ Value \\
\hline First day & 24 & 3 & 0.001 \\
Second day & 22 & 11 & 0.004 \\
Third day & 12 & 4 & 0.02 \\
Fourth day & 4 & 5 & 0.718 \\
\hline
\end{tabular}

Table 3. Respiratory Rate, Heart Rate, Need for Mechanical Ventilation, Oxygen Dependency, Mean Arterial Oxygen Pressure, and Mean Arterial $\mathrm{CO} 2$ Pressure in Study Groups

\begin{tabular}{|c|c|c|c|}
\hline Variable & $\begin{array}{r}\text { Group A } \\
(\mathbf{n}=30) \\
\end{array}$ & $\begin{array}{l}\text { Group B } \\
(\mathrm{n}=30)\end{array}$ & $P$ Value \\
\hline \multicolumn{4}{|c|}{ Respiratory rate } \\
\hline Before & $73.9 .94 \pm 33$ & $6.25 \pm 67.83$ & 0.022 \\
\hline After & $58.33 \pm 11.47$ & $52.83 \pm 11.11$ & 0.068 \\
\hline \multicolumn{4}{|c|}{ Heart rate } \\
\hline Before & $141.5 \pm 8.32$ & $139.56 \pm 12.91$ & 0.556 \\
\hline After & $142.16 \pm 17.05$ & $10.52 \pm 134.36$ & 0.011 \\
\hline \multicolumn{4}{|c|}{ Need for MV } \\
\hline Before & $21(70 \%)$ & 0 & 0.001 \\
\hline After & $18(60 \%)$ & 0 & 0.001 \\
\hline \multicolumn{4}{|c|}{ Respiratory distress } \\
\hline Before & 30 & 27 & 0.001 \\
\hline After & 22 & 5 & 0.076 \\
\hline \multicolumn{4}{|c|}{ Mean Po2 } \\
\hline Before & $591.7 \pm 2.8$ & $53.46 \pm 8.79$ & 0.562 \\
\hline After & $64.36 \pm 6.18$ & $63.86 \pm 9.71$ & 0.988 \\
\hline \multicolumn{4}{|c|}{ Mean PCo2 } \\
\hline Before & $37.4 \pm 6.92$ & $37.83 \pm 6.41$ & 0.805 \\
\hline After & $36.56 \pm 2.6$ & $35.83 \pm 4.78$ & 0.268 \\
\hline
\end{tabular}

in group A infants and $3.51 \pm 1.5$ days in group B infants $(P=0.459)$. Table 2 shows detailed data for those needing an additional dose during the trial. During the trial 27 (45\%), 33 (55\%), $16(26.7 \%)$, and 9 (15\%) infants required an additional dose on the first, second, third, and fourth day, respectively. Among all study infants, mean weight at the time of discharge was $2.82 \pm 0.57 \mathrm{~kg}$; mean weights at discharge of infants in groups A and B were $2.87 \pm 0.56 \mathrm{~kg}$ and $2.76 \pm 0.58 \mathrm{~kg}$, respectively $(P=0.532)$.

Table 3 summarizes the data on respiratory rate, heart rate, need for mechanical ventilation, respiratory distress, mean arterial oxygen pressure, and mean arterial $\mathrm{CO} 2$ pressure in the 2 study groups. Mean respiratory rates were $70.58 \pm 8.68$ per minute before and $55.58 \pm 11.53$ per minute after intervention in all infants $(P=0.00)$.
The mean respiratory rate was significantly decreased in each group after intervention; however, the means were not significantly different between the 2 groups after intervention $(P=0.068)$. Mean heart rates were 140 \pm 10.81 per minute before and $138.26 \pm 14.58$ per minute after intervention in the study individuals $(P=0.171)$. Infants in group B had a significantly lower heart rate after intervention $(P=0.011)$. Before intervention $21(35 \%)$ infants and after intervention $18(30 \%)$ infants needed mechanical ventilation $(P=0.001)$. Mean arterial oxygen pressure was $53.13 \pm 8.3 \mathrm{~mm} \mathrm{Hg}$ before intervention, and it was $64.11 \pm 8.07 \mathrm{~mm} \mathrm{Hg}$ after intervention in the study individuals $(P=0.001)$. There was no significant difference between the 2 groups for mean arterial oxygen pressure after intervention $(P=0.988)$. The means for arterial $\mathrm{CO} 2$ pressure were $37.61 \pm 6.61 \mathrm{~mm} \mathrm{Hg}$ before and $36.2 \pm 3.83 \mathrm{~mm} \mathrm{Hg}$ after intervention $(P=0.165)$. There was no significant difference between the 2 groups after intervention $(P=0.268)$.

Pneumothorax was present in only 1 infant, pneumonia in $13(21.7 \%)$ infants, intraventricular hemorrhage in $3(5 \%)$ infants, and patent ductus arteriosus (PDA) in $6(10 \%)$ infants. The most prevalent drug complication was restlessness with $8(13.3 \%)$ cases, followed by seizure $(10 \%)$, apnea $(6.7 \%)$, respiratory depression $(1.7 \%)$, and drowsiness (1.7\%).

\section{Discussion}

The current study found no significant difference between the study groups for mean length of hospitalization; all study individuals were hospitalized for a mean of 10 days. Furthermore, there was no significant difference between the 2 groups for mean duration of mechanical ventilation. Although mean respiratory rate was significantly decreased in both groups after intervention, there was no significant difference between the 2 groups for mean respiratory rate. In contrast, mean heart rate was significantly lower in group B infants after intervention. Mean arterial oxygen pressure was significantly improved after intervention, but this improvement was not significantly different between the 2 groups. In addition, mean arterial CO2 pressure was not significantly decreased after intervention in either study group.

Some previous studies have assessed the sedative effects of fentanyl and its different doses on neonates who undergo mechanical ventilation. Ancora et al assessed the superiority of infusion and bolus administration of fentanyl in infants who undergo mechanical ventilation. Mechanically ventilated infants under 37 weeks gestational age were randomly allocated to groups for continuous infusion of fentanyl, placebos, and open-label boluses. The authors concluded that fentanyl infusion did not reduce prolonged pain; however, it was effective on acute pain. ${ }^{14}$

In another similar study, Roth et al evaluated the analgesic and sedative effects of fentanyl on infants undergoing mechanical ventilation for RDS. Infants in the intervention group received a fentanyl infusion at a mean 


\section{Research Highlights}

\section{What Is Already Known?}

Fentanyl is used in different dosages ranging from $0.5 \mu \mathrm{g} /$ $\mathrm{kg}$ to $4 \mu \mathrm{g} / \mathrm{kg}$ for sedating infants with the same outcomes.

\section{What This Study Adds?}

We found that prescription of both $0.5 \mu \mathrm{g} / \mathrm{kg}$ and $1 \mu \mathrm{g} /$ $\mathrm{kg}$ doses of fentanyl effectively reduces all parameters of respiratory distress such as heart rate and respiratory rate; however there is no significant difference between 2 groups.

dosage of $0.68 \pm 0.24 \mu \mathrm{g} / \mathrm{kg} / \mathrm{h}$; these infants needed fewer sedatives and catecholamines in comparison to the control group. The authors concluded that fentanyl did not change heart rate or blood pressure. Their findings are not in line with those of the present study. Later meconium excretion and higher bilirubin levels were reported as side effects of fentanyl, the prescription of which has been suggested under indications. ${ }^{15}$

Guinsburg et al evaluated the response of ventilated neonates to a single dose of fentanyl $(3 \mu \mathrm{g} / \mathrm{kg})$ before, 30 minutes after, and 60 minutes after administration. They reported that minimum and maximum heart rates were decreased and growth hormone levels were increased after analgesia in the fentanyl group. The authors further concluded that behavioral measures of pain associated with mechanical ventilation were reduced in the fentanyl group. ${ }^{16}$

\section{Conclusion}

In conclusion, the findings of the present study suggest that doses of $0.5 \mu \mathrm{g} / \mathrm{kg}$ and $1 \mu \mathrm{g} / \mathrm{kg}$ fentanyl reduce all parameters of respiratory distress, including heart rate and respiratory rate; however, no significant difference between the 2 doses was observed.

\section{Authors' Contributions}

BN designed the study and collected the data. HE collected the data and helped with manuscript drafting. MHK analyzed the data and drafted the manuscript and critically revised it. All authors read and approved the final version of the manuscript.

\section{Conflict of Interest Disclosures}

The authors declare that they have no conflicts of interest.

\section{Ethical Approval}

This study was approved by the Ethics Committee of Islamic Azad University (Ref. No: IR.IAU.PS.REC.1395.28) and registered in the Iranian Registry of Clinical Trials (identifier: IRCT2017082517413N27, http://www.irct.ir/).

\section{Acknowledgments}

We are grateful to the Clinical Research Development Unit of Baqiyatallah Hospital for their kind collaboration.

\section{References}

1. Lynch RG. Surfactant and RDS in premature infants. Faseb J. 2004;18(13):1624.

2. Najafian B, Khosravi MH, Setayesh F, Shohrati M. Comparing the effect of Inhaler $\mathrm{N}$-acetyl cysteine and intravenous dexamethasone on respiratory distress syndrome in premature infants: a randomized clinical trial. Thrita. 2017;6(1):e46268. doi:10.5812/thrita.46268.

3. Behrman RE, Kliegman RM, Jensen HB. Nelson Textbook of Pediatrics. 2nd ed. Philadelphia: WB Saunders; 2000.

4. Iqbal Q, Younus MM, Ahmed A, et al. Neonatal mechanical ventilation: Indications and outcome. Indian J Crit Care Med. 2015;19(9):523-527. doi:10.4103/0972-5229.164800.

5. Najafian B, Karimi-Sari H, Khosravi MH, Nikjoo N, Amin S, Shohrati M. Comparison of efficacy and safety of two available natural surfactants in Iran, Curosurf and Survanta in treatment of neonatal respiratory distress syndrome: A randomized clinical trial. Contemp Clin Trials Commun. 2016;3:55-59. doi:10.1016/j.conctc.2016.04.003.

6. Hall RW, Boyle E, Young T. Do ventilated neonates require pain management? Semin Perinatol. 2007;31(5):289-297. doi:10.1053/j.semperi.2007.07.002

7. Najafian B, Esmaeili B, Khosravi MH. Comparison of fentanyl and midazolam for the sedation of infants under mechanical ventilation; a randomized clinical trial. Hosp Pract Res 2017;2(3):63-67. doi:10.15171/hpr.2017.17.

8. Hall RW, Shbarou RM. Drugs of choice for sedation and analgesia in the neonatal ICU. Clin Perinatol. 2009;36(2):215226. doi:10.1016/j.clp.2009.04.001.

9. Ibrahim M, Jones LJ, Lai NM, Tan K. Dexmedetomidine for analgesia and sedation in newborn infants receiving mechanical ventilation. Cochrane Database Syst Rev. 2016;(9):CD012361. doi:10.1002/14651858.CD012361.

10. Romantsik O, Calevo MG, Norman E, Bruschettini M. Clonidine for sedation and analgesia for neonates receiving mechanical ventilation. Cochrane Database Syst Rev. 2017;5:Cd012468. doi:10.1002/14651858.CD012468.pub2.

11. Bhandari V, Bergqvist LL, Kronsberg SS, Barton BA, Anand KJ. Morphine administration and short-term pulmonary outcomes among ventilated preterm infants. Pediatrics. 2005;116(2):352359. doi:10.1542/peds.2004-2123.

12. Tobias JD. Sedation and analgesia in the pediatric intensive care unit. Pediatr Ann. 2005;34(8):636-645. doi:10.3928/00904481-20050801-12.

13. Orsini AJ, Leef $\mathrm{KH}$, Costarino A, Dettorre MD, Stefano JL. Routine use of fentanyl infusions for pain and stress reduction in infants with respiratory distress syndrome. J Pediatr. 1996;129(1):140-145. doi:10.1016/S0022-3476(96)70201-9.

14. Ancora G, Lago P, Garetti E, etal. Efficacy and safety of continuous infusion of fentanyl for pain control in preterm newborns on mechanical ventilation. J Pediatr. 2013;163(3):645-651.e641. doi:10.1016/j.jpeds.2013.02.039

15. Roth B, Schlunder C, Houben F, Gunther M, Theisohn M Analgesia and sedation in neonatal intensive care using fentanyl by continuous infusion. Dev Pharmacol Ther. 1991;17(34):121-127.

16. Guinsburg R, Kopelman BI, Anand KJ, de Almeida MF, Peres Cde A, Miyoshi MH. Physiological, hormonal, and behavioral responses to a single fentanyl dose in intubated and ventilated preterm neonates. J Pediatr. 1998;132(6):954-959. doi:10.1016/ S0022-3476(98)70390-7. 